\title{
Relações Determinantes sobre as Despesas e as Receitas da Conta de Viagens Internacionais do Balanço de Pagamentos Brasileiro
}

\author{
Determinants in the credits and debits of \\ international travel account from the Brazilian Balance of Payments
}

Wilson Abrahão Rabahy ${ }^{1}$
José Carlos Domingos da Silva $^{2}$
Moisés Diniz Vassallo $^{3}$

\begin{abstract}
Resumo
O presente artigo busca relações causais da renda e, principalmente, a taxa de câmbio sobre as despesas dos brasileiros que viajam ao exterior e sobre as receitas advindas dos turistas estrangeiros que visitam o nosso país, dados estes mensurados na conta de turismo no Balanço de Pagamentos do Brasil. Os testes econométricos indicam que as despesas, em média, são afetadas pela taxa de câmbio real, enquanto as receitas não são. Ao analisar esta assimetria foi possível constatar outra, onde provou-se que o número de turistas de países fronteiriços, tendo os visitantes da Argentina como exemplo, em média, são sensíveis à taxa de câmbio real, enquanto os visitantes de países de outros continentes, tendo o número de visitantes dos Estados Unidos como parâmetro, não são afetados, em média, pela taxa de câmbio real.

Palavras-chave: economia do turismo; despesas de viagens internacionais; taxa de câmbio real.
\end{abstract}

\begin{abstract}
The present article looks for causal relations of the income and, especially, the exchange rate on the expenses of the Brazilians who travel abroad and on the revenues resulted from the foreign tourists who visit our country, these data measured in the account of tourism in the Brazilian Balance of Payments. Econometric tests indicate that the expenditure, on average, are affected by the real exchange rate, while the revenues are not.

While analyzing this asymmetry it was possible to note another one, which proved that the number of tourists from bordering countries, taking the visitors of Argentina as an example, on average, are sensitive to the real exchange rate. On the other hand the visitors from countries of other continents, taking the number of visitors from the United States as a parameter, are not affected, on average, by the real exchange rate.

Keywords: tourism economy; international travel account of balance of payments; real exchange rate.

\footnotetext{
${ }^{1}$ Professor Titular da Escola de Comunicação e Artes da Universidade de São Paulo. E-mail: rabahy@usp.br.

${ }^{2}$ Economista pela Pontifícia Universidade Católica de São Paulo e Mestre pelo Instituto de Pesquisas Econômicas da Universidade de São Paulo. E-mail: jcds@usp.br.

${ }^{3}$ Economista pela Universidade de São Paulo e Mestre pelo Instituto de Tecnologia da Aeronáutica. E-mail: vassallo@fipe.org.br.
} 


\section{Introdução}

Com a apreciação cambial contínua verificada no período recente, torna-se de suma importância uma análise quantitativa mais aprofundada da sensibilidade das despesas dos brasileiros no exterior e das receitas advindas dos gastos dos turistas estrangeiros que visitam nosso país frente a variações da taxa de câmbio real. Sendo esta análise quantitativa o objeto central deste artigo.

Ao final do ano de 2006, o total das Despesas de brasileiros com viagens internacionais, registradas na conta viagens internacionais do Balanço de Pagamentos brasileiro, totalizou US\$ 5,76 bilhões, contra US\$ 4,72 bilhões em 2005, observa-se assim um aumento nominal de aproximadamente $22 \%$ das Despesas no período citado. Do outro lado, as Receitas advindas dos gastos de estrangeiros no país (Receitas na conta de viagens internacionais), somaram, em 2006, cerca de US\$ 4,32 bilhões, saldo 11,8\% superior frente à soma verificada em 2005 . No primeiro semestre de 2007 as despesas já alcançaram a marca de US\$3,50 bilhões, cerca de 31\% superior ao montante de igual período de 2006. As receitas, no mesmo período de análise, totalizaram US\$ 2,44 bilhões, um crescimento de $10,9 \%$ em relação ao primeiro semestre de 2006 . Nota-se assim, que as despesas estão crescendo mais do que as receitas no período recente, o que à primeira vista, diante da apreciação cambial no período recente, era de se esperar.

Na tabela 1 está a evolução das despesas e das receitas da conta de turismo internacional, em dólares de 2006, deflacionadas pelo Índice de Preço ao Consumidor (IPC) dos Estados Unidos. De acordo com os dados, no período 2000-2006 as receitas cresceram, em termos reais, em média ao ano, 12,3\% enquanto as despesas cresceram 9,9\%. Nos anos 90, as receitas cresceram 0,4\% em média por ano e as despesas, no mesmo período, cresceram em média 8,9\%.

Ao analisar a tabela 1 , à luz das crises cambiais brasileiras nos últimos anos é possível notar um ponto interessante, ou seja, as diferentes respostas das despesas e das receitas frente às desvalorizações de 1999 e 2002. Em 1999, face à ruptura do sistema cambial vigente no país até então, as receitas cresceram 0,5\% em relação a 1998, por outro lado as despesas diminuíram 47,3\% em relação ao período anterior. Em 2002, ano em que também se observa uma crise cambial, as receitas cresceram somente $13,6 \%$ (visto que em outros períodos o crescimento foi mais acentuado), enquanto que as despesas caíram 26,3\%. Fica, desta forma, caracterizada a princípio uma assimetria no comportamento das receitas e despesas turísticas diante das 
oscilações cambiais brasileiras.

Tabela 1: Despesas e Receitas, a valores de 2006 (ajustados pelo IPC dos EUA)

\begin{tabular}{|c|c|c|c|c|c|}
\hline & \multicolumn{2}{|c|}{ Receitas } & \multicolumn{2}{c|}{ Despesas } & Saldo \\
\cline { 2 - 6 } & US\$ (bilhões) & $\begin{array}{c}\text { Variaçã } \\
\text { o Real }\end{array}$ & US\$ (bilhões) & $\begin{array}{c}\text { Variação } \\
\text { Real }\end{array}$ & $\begin{array}{c}\text { US\$ } \\
\text { (bilhões) }\end{array}$ \\
\hline 1990 & 2,30 & - & 2,44 & - & $-0,14$ \\
1991 & 1,60 & $-30,6 \%$ & 1,95 & $-20,1 \%$ & $-0,35$ \\
1992 & 1,53 & $-4,2 \%$ & 2,01 & $3,4 \%$ & $-0,48$ \\
1993 & 1,53 & $0,0 \%$ & 2,64 & $31,0 \%$ & $-1,11$ \\
1994 & 1,43 & $-6,6 \%$ & 3,04 & $15,0 \%$ & $-1,61$ \\
1995 & 1,29 & $-10,1 \%$ & 4,49 & $47,8 \%$ & $-3,20$ \\
1996 & 1,08 & $-16,0 \%$ & 5,70 & $27,1 \%$ & $-4,62$ \\
1997 & 1,34 & $24,4 \%$ & 6,84 & $19,9 \%$ & $-5,50$ \\
1998 & 1,96 & $46,1 \%$ & 7,09 & $3,6 \%$ & $-5,13$ \\
1999 & 1,97 & $0,5 \%$ & 3,73 & $-47,3 \%$ & $-1,76$ \\
2000 & 2,12 & $7,5 \%$ & 4,56 & $22,1 \%$ & $-2,44$ \\
2001 & 1,97 & $-7,0 \%$ & 3,64 & $-20,1 \%$ & $-1,67$ \\
2002 & 2,24 & $13,6 \%$ & 2,69 & $-26,3 \%$ & $-0,45$ \\
2003 & 2,72 & $21,3 \%$ & 2,48 & $-7,7 \%$ & 0,24 \\
2004 & 3,44 & $26,6 \%$ & 3,06 & $23,7 \%$ & 0,37 \\
2005 & 3,99 & $15,9 \%$ & 4,87 & $59,0 \%$ & $-0,89$ \\
2006 & 4,32 & $8,3 \%$ & 5,76 & $18,3 \%$ & $-1,45$ \\
\hline
\end{tabular}

Fonte: Banco Central do Brasil

Diante da exposição acima, o presente artigo, pretende quantificar as relações da taxa de câmbio real e da renda, com as despesas com viagens internacionais de brasileiros e com as receitas de viagens advindas de visitantes estrangeiros no Brasil.

O artigo está dividido em cinco partes incluindo esta seção introdutória. Na seção 2, apresentamse as relações econômicas esperadas para as despesas e para as receitas da conta de turismo internacional do Balanço de Pagamentos brasileiro. Na seção 3, são descritos os dados utilizados e a metodologia para estimar as relações propostas na seção anterior. $\mathrm{Na}$ seção 4, são reportados os resultados das estimações propostas. E, por fim, na seção 5, são tecidas as considerações finais. 


\section{As Relações Econômicas das Despesas e das Receitas}

Para estimar a sensibilidade, tanto do lado das despesas, quanto do lado das receitas, propõe-se testar econometricamente um modelo simplificado, que conta apenas com duas variáveis proxies, uma para quantificar o efeito-preço e outra para o efeito-renda sobre as despesas dos brasileiros que visitam o exterior e as receitas advindas das visitas de estrangeiros ao Brasil. Do lado das despesas, temos:

$$
D=D(\varepsilon, Y)
$$

Em palavras, que as despesas dos brasileiros que viajam para o exterior estão em função, em termos agregados, da renda ( $Y$, tendo o $\mathrm{PIB}^{4}$ como variável proxy para mensurar o efeito-renda) e da taxa de câmbio real ( $\varepsilon$, como proxy para mensurar o efeito-preço). Espera-se, de acordo com a teoria econômica, que elevações da renda, em média, elevem as despesas e que as depreciações do câmbio real tenha sentido contrário, ou seja, reduzam os gastos dos brasileiros no exterior, pois ficaria mais caro a "cesta de turismo" no exterior (sendo assim, uma apreciação da taxa de câmbio real tende a elevar as despesas). A variável câmbio real é dada pela seguinte expressão algébrica:

$$
\varepsilon=\frac{E P^{*}}{P^{d}}
$$

Onde: $\varepsilon$ é a taxa de câmbio nominal (R\$/US\$); $P^{*}$ é o nível de preços estrangeiro e $P^{d}$ é o nível de preços doméstico. A taxa de variação da taxa de câmbio real no tempo (em \%) pode ser decomposta da seguinte forma:

$$
\frac{\Delta \varepsilon}{\varepsilon}=\frac{\Delta E}{E}+\frac{\Delta P^{*}}{P^{*}}-\frac{\Delta P^{d}}{P^{d}}
$$

Desta forma pode-se dizer que a apreciação da taxa de câmbio nominal, tudo o mais constante, leva à apreciação da taxa de câmbio real. Como o nível de preço da economia brasileira, no período recente, está próximo dos níveis de preços das economias desenvolvidas, podemos inferir que as variações do câmbio real nos últimos anos estão atreladas principalmente às variações da taxa de câmbio nominal.

\footnotetext{
${ }^{4}$ É preciso ressaltar que o PIB muito embora possa não ser a melhor variável para mensurar o efeito-renda dos brasileiros que viajam ao exterior, foi tomado neste estudo devido a não disponibilidade de uma melhor proxy, com a periodicidade aqui utilizada.
} 
No gráfico a seguir são apresentadas as evoluções da taxa de câmbio real, do PIB e das despesas dos brasileiros no exterior. Como é possível observar, as despesas têm uma correlação negativa, porém simétrica, em relação à taxa de câmbio real na maior parte do período ilustrado no Gráfico 1 .

Gráfico 1: Despesas, PIB e taxa de câmbio real (dados trimestrais, em índice 1995.1=100)

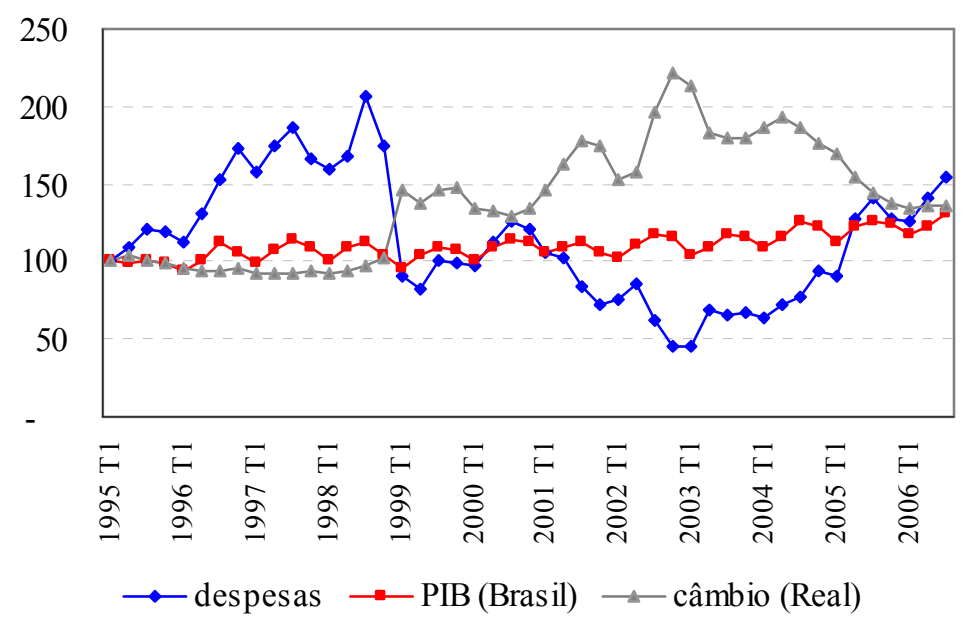

Fonte: Banco Central do Brasil e IBGE

Assim como no caso das despesas, pretende-se buscar um sentido de causalidade para as receitas de estrangeiros que viajam para o Brasil. Em princípio, tem-se que as receitas também dependem de fatores como renda e preço. Na busca destas evidências empíricas, testamos a seguinte relação para as receitas:

$$
R=R\left(\underset{+}{\varepsilon}, Y_{+}^{*}\right)
$$

Onde, $\varepsilon$ representa a taxa de câmbio real (a mesma apresentada para as despesas) para proxy do efeito-preço e $Y^{*}$ representa a variável para o efeito-renda-mundo. Nos modelos empíricos foram utilizadas as exportações mundiais como proxy, para renda do mundo, pois estas são tradicionalmente utilizadas como indicadores da atividade econômica mundial. Os sinais esperados seriam: elevações da renda mundial elevariam as receitas (despesas de estrangeiros que viajam para o Brasil) e depreciações da taxa de câmbio real tenderiam a elevar as receitas. A seguir, no gráfico 2, é mostrada a evolução das receitas e das exportações mundiais nos últimos anos. 
Gráfico 2: Receitas e as exportações mundiais (em índice 1995.1=100)

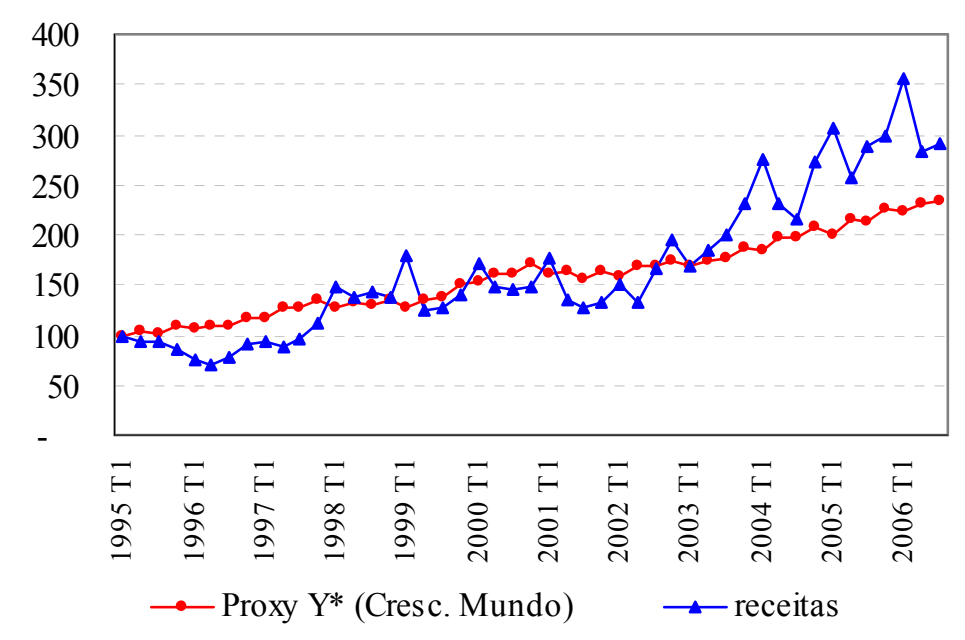

Fonte: Banco Central do Brasil e IFS/IMF

\section{Sobre os Dados e a Metodologia Utilizada}

Em relação aos testes econométricos, buscou-se duas linhas de análise, uma de longo prazo, pela metodologia de co-integração de Johansen (JOHANSEN, 1988 e 2004; HAMILTON, 1994; ENDERS, 1995) e outra de curto prazo, cujo instrumental foi o de Mínimos Quadrados Ordinários (MQO) na primeira diferença.

A metodologia de co-integração utilizada em séries temporais permite identificar se existe uma relação de equilíbrio de longo prazo entre determinadas variáveis econômicas e a velocidade de ajustamento aos desequilíbrios de curto prazo. Quando as variáveis do modelo co-integram, dizse que, mesmo havendo uma tendência estocástica, as mesmas evoluem ao longo do tempo de forma sincronizada, podendo a relação apresentar apenas desvios de curto prazo.

A maioria das séries econômicas (macroeconômicas) apresenta uma tendência estocástica que pode levar a conclusões equivocadas com respeito causalidade e a relação entre determinadas variáveis, ou seja, pode-se estar diante de um problema de regressão espúria (regressão sem sentido). Um exemplo onde é possível a ocorrência deste fenômeno é quando da utilização de MQO na busca de relações causais com as variáveis no nível, mantendo desta forma tendências estocásticas, é possível obter-se relações significantes, mas que podem não estarem associadas a uma relação de causalidade. 
O problema de regressão espúria, através do método de MQO, pode ser eliminado, quando estamos diante de séries não estacionárias (com tendência estocástica), por meio de uma transformação da primeira diferença das séries de tempo ${ }^{5}$. Aplicando a primeira diferença às séries, se as mesmas forem integradas de ordem 1, elimina-se a tendência, o problema central da regressão espúria. Contudo, tal procedimento, faz com que as informações de longo prazo sejam perdidas. Por isso, adotou-se esta metodologia apenas para a etapa de identificação das relações de curto prazo.

No que diz respeito ao tratamento dos dados, todas as variáveis testadas estão em termos reais e passaram por transformação logarítmica, apresentando uma periodicidade trimestral (1995.1 a 2005.4), e com exceção da taxa de câmbio real, todas as demais variáveis passaram por ajuste sazonal.

A taxa de câmbio real foi construída de acordo com uma média ponderada por conta dos pesos dos principais parceiros comerciais do Brasil no que tange à taxa de câmbio nominal e o índice de preço externo. Neste último caso, utilizou-se como parâmetro o IPC - Índice de Preço ao Consumidor - de cada país. O IPCA (Índice de Preço ao Consumidor - Amplo) do IBGE foi utilizado como deflator do nível de preços doméstico da taxa de câmbio real.

Para o efeito da análise de co-integração, foram realizados testes de raiz unitária (DICKEY e FULLER, 1979 e 1981; PHILLIPS e PERRON, 1988), onde ficou evidenciado que as variáveis propostas no modelo são integradas de ordem 1, ou seja, apresentaram uma raiz unitária. Em outras palavras, cada série de tempo utilizada apresenta uma tendência estocástica. Sendo assim, a metodologia de MQO para se estimar a relação de longo prazo não seria adequada.

\section{Resultados Econométricos para a Relação das Despesas e Para as Receitas}

\subsection{As Despesas de Brasileiros no Exterior}

De acordo com o modelo testado para as despesas, não é possível rejeitar a hipótese de que as variáveis analisadas são co-integradas. Pela metodologia proposta, apurou-se um vetor de cointegração. A tabela a seguir mostra os resultados para a relação de longo prazo e a velocidade de ajustamento de curto prazo.

\footnotetext{
${ }^{5}$ A primeira diferença no tempo para uma variável $y$ qualquer pode ser mensurada como: $\Delta y_{t}=y_{t}-y_{t-1}$.
} 
Tabela 2: Relação de longo prazo e velocidade de ajuste de curto prazo

\begin{tabular}{lrl}
\hline & Betas & \multicolumn{1}{c}{ Alfas } \\
\hline Ln(Despesas) & 1 & 0,4731 \\
Ln(Câmbio) & $-1,51$ & $-0,0228\left(^{*}\right)$ \\
Ln(PIB) & 2,67 & $-0,0001\left(^{*}\right)$
\end{tabular}

(*) não significantes a 10\% pelo teste de razão-verossimilhança.

Na tabela 2, os betas indicam as elasticidades de longo prazo. A relação de longo prazo diz que: de um lado, uma elevação da renda em 1\%, no longo prazo, eleva as despesas em 2,67\%. De outro lado, uma apreciação, ou seja, redução do câmbio real em 1\%, eleva em 1,51\% as despesas dos brasileiros em viagens no exterior. Em termos algébricos temos, no longo prazo, a seguinte função para as despesas:

$$
\operatorname{Ln}(D)=2,668 \operatorname{Ln}(P I B)-1,506 \operatorname{Ln}(\text { Câmbio })
$$

Quando as variáveis co-integram diz-se que as mesmas apresentam uma relação de equilíbrio de longo prazo. Contudo, isso não implica que não exista desequilíbrio de curto prazo. Os alfas indicados na tabela 2 retratam, em princípio, a velocidade de ajustamento das variáveis do modelo caso haja desequilíbrios de curto prazo. Para que a relação volte ao equilíbrio de longo prazo $47,3 \%$ do ajuste é realizado pelas despesas no primeiro trimestre em que há desequilíbrio. Com base nos resultados dos parâmetros alfas também pode-se concluir, como era de se esperar, que o PIB e a taxa de câmbio real são variáveis exógenas no modelo, ou seja, somente as despesas se ajustam para levar a relação ao equilíbrio de longo prazo.

A relação de curto prazo foi estimada por MQO aplicando a primeira diferença nas séries utilizadas. Levou-se em conta ainda a defasagem de um período para a primeira diferença do PIB $(Y)$ e dois períodos para o câmbio real $(\varepsilon)$. Em termos algébricos, o modelo testado foi:

$$
\Delta D_{t}=\beta_{0}+\beta_{1} \Delta \varepsilon_{t}+\beta_{2} \Delta Y_{t}+\beta_{3} \Delta \varepsilon_{t-1}+\beta_{4} \Delta Y_{t-1}+\beta_{4} \Delta \varepsilon_{t-2}
$$

Onde, $\Delta$ representa o operador da primeira diferença da série utilizada e $\beta_{0}$ é o coeficiente linear da equação. Os demais betas refletem a sensibilidade das despesas em relação ao parâmetro testado. 
Os resultados indicados na tabela 3 evidenciam a existência de correlação inversa entre o câmbio real e as despesas de brasileiros no exterior estatisticamente significante, tanto no período contemporâneo, quanto no período imediatamente anterior. Isso comprova a proposição de que a apreciação do câmbio favorece o aumento dos gastos, além de contribuir para o aumento do número de saídas de brasileiros para o exterior. Os resultados indicam ainda que no curto prazo a renda não é um fator determinante para as despesas dos brasileiros que viajam ao exterior.

Tabela 3: Relação de Curto Prazo

\begin{tabular}{|l|r|r|r|r|}
\hline \multicolumn{5}{|c|}{ Variável Dependente: Despesas } \\
\hline Variáveis & Coeficiente & Erro-padrão & Estatística t & P-valor \\
\hline Constante & 0,001 & 0,023 & 0,060 & 0,952 \\
\hline$\Delta$ Câmbio & $-1,237$ & 0,174 & $-7,108$ & 0,000 \\
\hline$\Delta$ PIB & 0,053 & 0,816 & 0,065 & 0,948 \\
\hline$\Delta$ Câmbio (t-1) & $-0,542$ & 0,179 & $-3,030$ & 0,004 \\
\hline$\Delta$ PIB (t-1) & 0,727 & 0,796 & 0,914 & 0,366 \\
\hline$\Delta$ Câmbio (t-2) & 0,268 & 0,174 & 1,533 & 0,133 \\
\hline R- Quadrado & 0,694 & & & \\
Estatística F & 17,198 & & & \\
Prob (Estatística F) & 0,000 & & & \\
\hline
\end{tabular}

\subsection{As Receitas dos Turistas Estrangeiro que Visitam o Brasil}

Tanto a relação de longo prazo quanto a de curto prazo também foram testadas para as receitas de estrangeiros que viajam para o Brasil. Pela metodologia de co-integração é possível rejeitar a hipóteses de que existe uma relação de equilíbrio de longo prazo no período testado, logo, temos que as variáveis testadas não co-integram. Os resultados obtidos dizem que, em termos agregados, a renda e o preço (caracterizado pela taxa de câmbio real) não apresentam uma relação de equilíbrio de longo prazo.

Ainda em relação às tentativas de estimativas das relações entre as receitas, o câmbio real e o termo de renda mundial $\left(Y^{*}\right)$, a seguir é apresentado um dos modelos testados para o curto prazo.

$$
\Delta R_{t}=\beta_{0}+\beta_{1} \Delta \varepsilon_{t}+\beta_{2} \Delta Y_{t}^{*}+\beta_{3} \Delta Y_{t-1}^{*}+\beta_{4} \Delta \varepsilon_{t-1}
$$

Como indicado nos resultados econométricos, por MQO, para a relação acima, contidos na tabela 
4, a elasticidade para o câmbio real não é estatisticamente significativa, aos valores estatísticos usuais, em termos de relação causal para explicar as Receitas no curto prazo. Por outro lado, o que se revela significativo é o termo que reflete o crescimento econômico mundial (variável proxy para se mensurar o efeito-renda) no período imediatamente anterior (em $t-1$ ), um resultado até certo ponto intuitivo, pois o aumento da renda tende a impactar nas viagens em períodos subseqüentes ao ganho devido ao tempo de planejamento de uma viagem internacional.

Tabela 4: Relação de Curto Prazo

\begin{tabular}{|l|c|cr|r|}
\hline \multicolumn{4}{|c|}{ Variável Dependente: Despesas } \\
\hline Variáveis & Coeficient & Erro-padrã Estatística & P-valor \\
\hline Constante & $-0,021$ & $0,02 \Phi$ & $-0,714$ & 0,479 \\
\hline$\Delta$ Câmbio & 0,351 & 0,231 & 1,520 & $0,13 \phi$ \\
\hline$\Delta$ Export. Mundo & 0,333 & $0,63 \$$ & 0,524 & 0,603 \\
\hline$\Delta$ Câmbio (t-1) & $-0,230$ & 0,239 & $-0,965$ & 0.340 \\
\hline$\Delta$ Export. Mundo (t-1) & 2,104 & 0,624 & 3.319 & 0.001 \\
\hline R- Quadrado & 0,353 & & & \\
Estatística F & 5,451 & & & \\
Prob (Estatística F) & 0,001 & & & \\
\hline
\end{tabular}

Em princípio, era de se esperar que uma desvalorização cambial atraísse mais turistas estrangeiros ao país. Entretanto, tal fato pode ser verdadeiro ou não dependendo da distância do país de origem e da sensibilidade a preços dos turistas que visitam o Brasil. Por exemplo, os turistas advindos de países que fazem fronteira com o Brasil podem ter uma sensibilidade em relação à taxa de câmbio real diferente dos turistas advindos de outros continentes. A tese aqui defendida é que o turista argentino e uruguaio, por exemplo, respondem, em média, à variações da taxa de câmbio real, fato pouco provável ao turista europeu ou norte americano. Na média, os turistas de outros continentes provavelmente levam em conta outros fatores, como por exemplo, o diferencial do produto turístico brasileiro e a exclusividade de atrações o que torna a demanda pelo produto oferecido para esses turistas inelástica ao preço.

Tendo como uma hipótese que os turistas de países que fazem fronteira com o Brasil são mais sensíveis ao câmbio real, coloca-se uma questão: como explicar a redução (ou o não crescimento substancial) do número de visitantes vindos da Argentina em períodos pós desvalorização (aguda) da taxa de cambial brasileira? Por exemplo, em outubro de 2002 a taxa de câmbio 
nominal atingiu o patamar de R\$ 3,81/US\$ $1^{6}$. A taxa de câmbio nominal média de 2003 se depreciou em $31 \%$ em relação à taxa média de 2001 , enquanto o número de turistas argentinos reduziu em aproximadamente 42,7\%, em 2003, frente ao total verificado em 2001.

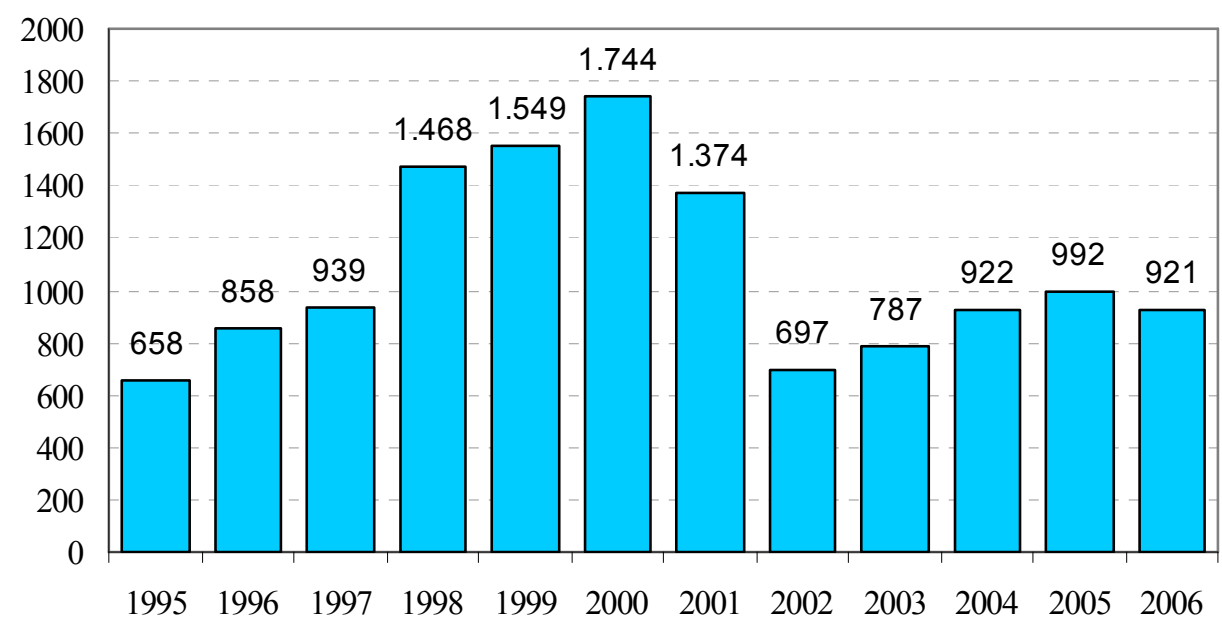

Gráfico 3: Evolução do número de visitantes da Argentina (em mil) Fonte: EMBRATUR

Parte da resposta à pergunta colocada talvez seja, inicialmente, obtida analisando os Gráficos 3 e 4. No mesmo período em que houve a desvalorização cambial brasileira a Argentina também passou por uma crise cambial, com um agravante, com a redução do PIB em termos reais. O gráfico abaixo ilustra a evolução do PIB real da Argentina e a taxa de câmbio real entre o Brasil e a Argentina. Em relação à taxa de câmbio real Brasil/Argentina, mesmo diante da desvalorização do Real perante o dólar em 2002, observa-se um movimento de apreciação da moeda brasileira, visto que a desvalorização da moeda argentina frente ao dólar foi muito mais intensa. Em 2002, o PIB da Argentina recuou 10,9\% e a economia argentina ainda enfrentou uma desvalorização da taxa de câmbio nominal em mais de $200 \%$ em relação à taxa média verificada em 2001 .

\footnotetext{
${ }^{6}$ Câmbio comercial (venda), média mês.
} 
Gráfico 4: Evolução do PIB da Argentina e da taxa de câmbio real ${ }^{7}$, em índice 1990=100

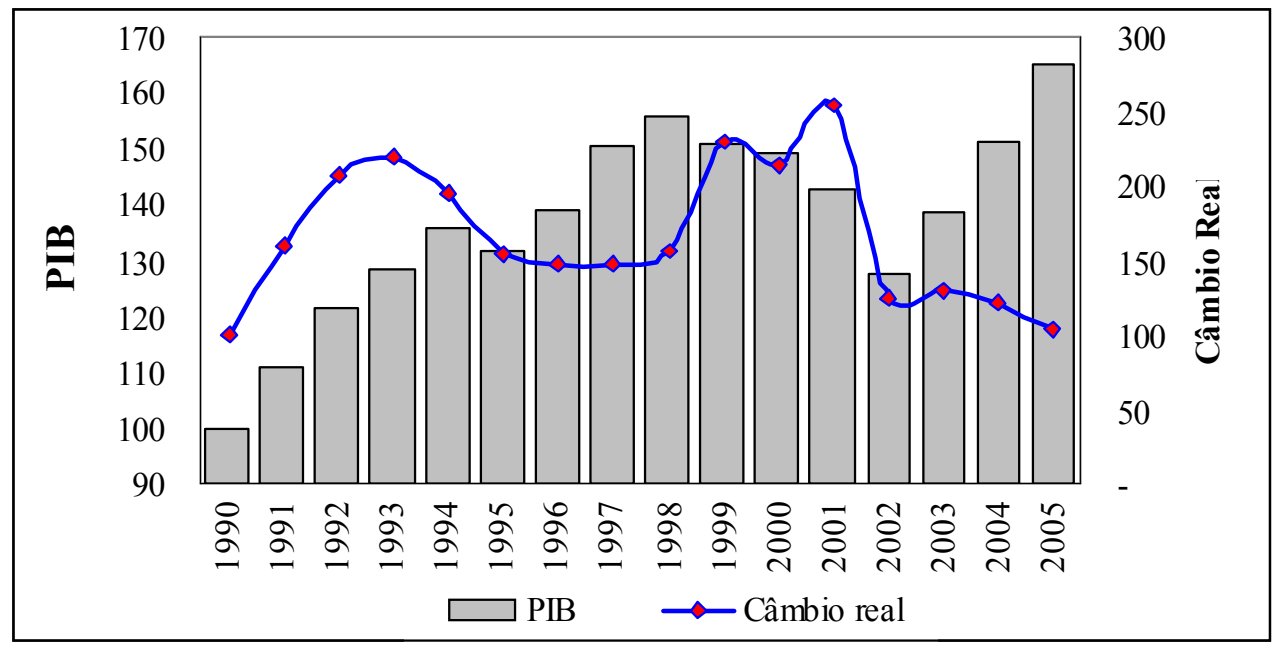

Fonte: IFS/IMF e Banco Central do Brasil

Com o intuito de buscar evidências de que o câmbio real afeta de forma diferente as receitas advindas de países fronteiriços e de países de outros continentes testou-se a existência de uma relação de equilíbrio de longo prazo entre o número de turistas da $\operatorname{Argentina~}^{8}$ que visitam o Brasil (Visit), o PIB da Argentina e o câmbio real (entre Brasil e Argentina). Os testes de co-integração indicam que existe uma relação de equilíbrio de longo prazo entre as variáveis testadas. Abaixo segue a relação de longo prazo e a velocidade de ajustamento indicada pelos testes de co-integração ${ }^{9}$.

Tabela 5: Relação de longo prazo e velocidade de ajuste de curto prazo

\begin{tabular}{lrl}
\hline & Betas & \multicolumn{1}{c}{ Alfas } \\
\hline Ln(Despesas) & 1 & 0,232 \\
Ln(Câmbio) & 2,34 & $0,031(*)$ \\
Ln(PIB) & 2,30 & $-0,058(*)$
\end{tabular}

(*) não significantes a 10\% pelo teste de razão-verossimilhança

$$
\operatorname{Ln}(\text { Visit })=17,86+2,30 \operatorname{Ln}(P I B)+2,34 \operatorname{Ln}(\text { Câmbio })
$$

${ }^{7} \varepsilon=\frac{\left(\frac{R \$}{\text { Peso Argentina }}\right) \times I P C \text { Argentina }}{I P C A \text { Brasil }}$.

${ }^{8} \mathrm{O}$ número de turistas serve como uma variável de aproximação para os gastos dos visitantes argentinos no país. Sendo a Argentina o maior emissor de turistas para o Brasil entre os países fronteiriços.

${ }^{9}$ Parâmetros estatisticamente significantes aos níveis usuais. 
Ou seja, tudo o mais constante, uma desvalorização de 1\% do câmbio real Brasil/Argentina eleva em $2,34 \%$ o número de visitantes argentinos.

O mesmo teste foi realizado em relação aos turistas advindos dos Estados Unidos ${ }^{10}$. Os testes de co-integração, para este caso, indicam que não há uma relação de equilíbrio de longo prazo entre o número de turistas dos Estados Unidos que visitam o Brasil e a taxa de câmbio real ${ }^{11}$ e o PIB da dos Estados Unidos. Testou-se ainda uma relação de curto prazo, nos moldes testados anteriormente, verificando-se que somente o coeficiente relacionado à renda (no período imediatamente anterior, em t-1) se mostrou estatisticamente significante.

Sendo assim, para estes dois exemplos, Argentina e Estados Unidos, fica evidenciado que a taxa de câmbio real tem efeitos assimétricos sobre a vinda de turistas destes países ao Brasil.

\section{Considerações finais}

Os resultados obtidos neste trabalho indicam, de um lado, que as Despesas de brasileiros que viajam ao exterior são, em média, influenciadas pela taxa de câmbio real, tanto no curto quanto no longo prazo. Sendo que no longo prazo, a relação de equilíbrio indica que, por exemplo, uma apreciação em $1 \%$ da taxa de câmbio real, tudo o mais constante, elevaria em 1,51\% as Despesas de brasileiras que viajam ao exterior.

De outro lado, as Receitas, em termos agregados, advindas do total de turistas que viajam ao Brasil, em média, não são afetadas pela taxa de câmbio real. Na relação de curto prazo, somente a renda (com um período de defasagem) mostrou-se estatisticamente significante para explicar as relações causais das Receitas. Diante deste resultado, colocou-se em questão a possível resposta assimétrica da taxa de câmbio em relação aos turistas de países fronteiriços e dos provenientes de outros continentes. Ao final dos testes econométricos, ficou evidenciada tal assimetria para os

${ }^{10}$ Maior emissor de turistas para o Brasil entre os países de outros continentes.

${ }_{11} \varepsilon=\frac{\left(\frac{R \$}{\mathrm{US} \$}\right) \times I P C \text { EUA }}{I P C A \text { Brasil }}$ 
turistas da Argentina e dos Estados Unidos. O número de turistas argentinos que visitam o Brasil mostrou-se sensível em relação à taxa de câmbio real e a renda, enquanto os visitantes dos Estados Unidos, em média, não são sensíveis em relação à taxa de câmbio real, somente em relação à renda com um período de defasagem.

Para finalizar, é preciso ressaltar que a linha de pesquisa apresentada neste trabalho tem grande potencial de avanço, sobretudo em relação aos resultados indicados para as receitas, ampliando a amostra de visitantes de outros países (fronteiriços e de outros continentes) para se obter resultados mais robustos frente aos resultados incipientes, porém representativos e significativos, apresentados neste artigo.

\section{Referências Bibliográficas}

BANCO CENTRAL DO BRASIL. Estatísticas. 1990-2006. Brasília: Banco Central

DICKEY, D. A. e FULLER, W. A. 1979. Distribution of the estimator for autoregressive time series with a unit root. Journal of the Statistical Association. vol. 74.

Econometrica. Vol. 49, 1981. Likelihood ratio statistic for autoregressive time series with a unit root.

EMBRATUR. 2007. Anuário Estatístico Embratur, 1996-2007. Brasília: EMBRATUR.

ENDERS, W. 1995. Applied econometric time series. New York: Wiley.

HAMILTON, J. D. 1994. Time series analysis. Princeton: Princeton University Press.

JOHANSEN, S. 1988. Statistical analysis of cointegration vectors. Journal of Economic Dynamic and Control. vol. 12.

. 2004. Cointegration: an Overview. In: T.C. Mills and K. Patterson (eds.) Handbook of Econometrics: Volume 1, Econometric Theory, NY: Palgrave MacMillan.

PHILLIPS, P.C.B. e PERRON, P. 1988. Testing for a unit root in time series regression. Biometrica. Vol. 75.

Recebido em: 10/10/2007 ( $1^{\mathrm{a}}$ versão) $29 / 02 / 2008$ ( $2^{\mathrm{a}}$ versão)

Aprovado em: 04/03/2008 